\title{
Sintoma de nossos tempos: representações do ideal adolescente em matérias sobre parricídio
}

Mariana Duccini

\section{Resumo:}

Este artigo pretende analisar, em duas reportagens publicadas pela revista semanal de informação Época, no ano de 2002, de que maneira as estratificações sociais, em terminologia de S. Moscovici, respaldam a construção de representações sociais tangentes a um crime de parricídio, mobilizando configurações imaginárias que dizem respeito, sobretudo, a um ideal de adolescência típico de nossos tempos. Considerando-se uma característica inerente à dinâmica dos discursos, qual seja, a de falar em nome de uma vontade de verdade que traduz articulações de um jogo de poder - o poder de instalar significados socialmente aceitos -, o estudo tentará depreender de que maneira tais vontades de verdade se materializam, em um discurso midiático, estabelecendo parâmetros de legitimação relativos às práticas e condutas sociais.

\section{Palavras Chave:}

representações sociais; ideal de adolescência; revistas; parricídio; comunicação

\section{Abstract:}

This text aims to analyze, in two articles published by the Brazilian weekly magazine Época, in 2002, how social stratifications (according to Serge Moscovici's point of view) undertake the constructions of certain social representations on a crime of parricide. We consider the idea of an imaginary order whose configurations refer to the adolescence as a contemporary cultural ideal. Taking into account an inherent feature of discourse practices, which speaks on behalf of a will to truth relationed to power injunctions, the study attempts to infer how these arrangements appear in the magazine articles and underlie guidelines on social practices and conducts.

\section{Keywords:}

social representations; adolescence as a cultural ideal; weekly magazines; parricide; communication

O mundo tal qual o concebemos não se constitui como um dado imanente, autorreferencial, suficiente per se: a cada tempo e a cada lugar específicos à trajetória das sociedades corresponde uma predisposição relativa a modos de ver e de se valorar aquilo que é visto - em última instância, uma maneira específica de se apreender o que é da ordem desse universo. Mais além, esses vetores dizem respeito a formas de ser e de estar no mundo. Se a um tempo legitimam posições e papéis sociais em termos de euforia e de disforia, tais plataformas, concomitantemente, derivam-se de (e fazem derivar) um efeito de naturalização: emerge, pois, um verdadeiro do mundo, na acepção de Foucault (2002), cuja especificidade é a de sobredeterminação: os discursos em circulação (aqui entendidos como práticas sociais que se institucionalizam como tributárias da própria organização social) têm como referência tal verdadeiro do mundo, buscando, de uma maneira ou de outra, falarem em nome dele, conformarem-se a ele (ainda que em posição de não-concordância explícita, literal) como condição radical de existência, posto que de legitimidade. 
No terreno das mídias, esses parâmetros articulam inferências sobre as expectativas de rebatimento - ou de reiteração -, na pretensão do "encaixe" dos discursos circulantes em determinadas estratificações, na terminologia de Moscovici (2003). Bases que determinam os sentidos das práticas sociais (sendo mutáveis em vista de diferentes tempos e lugares), as estratificações operacionalizam efeitos de constrangimento dos discursos, na medida em que a dinâmica própria a elas diz respeito à busca de filiações das narrativas a campos estabilizados. Tal ordem de reiteração viabiliza um duplo movimento: a legitimação de certos discursos recorrentes (pela frequência com que rebatem no campo), assim como a própria constituição do campo.

A primeira inferência subsumida dessas formulações é que o estatuto comumente nomeado como realidade só se constitui como materialização discursiva, a se ter em vista a assunção (independentemente do caráter volitivo) dos indivíduos a uma ordem específica (a qual será referencializada mais adiante), que a rigor os converte em sujeitos e coloca em perspectiva o estabelecimento de laços sociais. Essa ordem é, ela própria, o que garante a possibilidade da organização social.

Como derivação, infere-se que não há, portanto, maneira de se conceber a atuação das mídias em autonomia a essa lógica, ou seja, em um campo organizado extradiscursivamente. Elas são constituídas no e pelo discurso, visto que configuram também uma instituição social, sendo tributárias das plataformas de cultura que aqui aparecem sob a nomenclatura de estratificações.

Torna-se relevante, por fim, uma ilação decorrente dessa "existência no discurso" que configura a própria condição dos meios de comunicação. Se eles respondem à mesma dinâmica de filiação a determinadas (con)formações que operam na ordem da estabilização, da normalização e da legitimação - de resto, como é próprio a toda prática social, cujo fim é engendrar discursivamente uma verdade própria - é razoável inferir que as representações articuladas em termos de um exercício midiático (os "acontecimentos", os atores sociais, as crenças e os saberes) obedeçam também a um regime de restrições, adaptações e mobilizações de significados que emanam de uma disposição de verdade que traduz, em si, articulações de poder.

Essas relações, ao cabo, determinam os parâmetros de legitimidade que recobrem as representações sociais e que concedem, a rigor, o direito à voz, por meio da qualificação (ou da desqualificação) daqueles que tomam, ao menos hipoteticamente, a palavra. As formulações de Foucault (1979) sobre o estatuto da loucura são, assim, exemplares no que se refere, de maneira mais ampla, à positividade do poder no sentido de instalar um direito inerente e inquestionável ao estatuto da norma. Para além das figurativizações de verdade daí decorrentes, essa presunção de direito determinará, também, procedimentos, ações, "modos de fazer" - a um tempo: parâmetros de inclusão e de exclusão, via discurso, de certos atores e de certas configurações sociais:

Aquilo que estava logo de início implicado nestas relações de poder era o direito absoluto da nãoloucura sobre a loucura. Direito transcrito em termos de competência exercendo-se sobre uma ignorância, de bom senso no acesso à realidade corrigindo erros (ilusões, alucinações, fantasmas), de normalidade se impondo à desordem e ao desvio. (FOUCAULT, 1979:127)

A atuação das mídias no sentido da normatização, portanto, aproxima-se de um movimento em nome da desarticulação, da impossibilidade radical de inclusão constitutiva de tudo quanto diga respeito à 
desordem - sob ameaça do próprio aniquilamento das instituições sociais que se estruturam como processos dos jogos de poder. Há que se levar em conta, naturalmente, as dissimetrias e tensões inerentes às constituições de campo - a própria regulação que determina "o que está dentro" (recoberto de legitimação) e "o que está fora" (no espaço pantanoso da anomia) não emerge como uma condição estanque. Ocorre, entretanto, que a interdição opera em diferentes âmbitos, desde a pura e simples exclusão até a assimilação (que por vezes se transfigura como inevitável) de certos discursos outrora anômicos, com a finalidade de administrá-los, investi-los em um horizonte conhecido, previsível.

A filiação a um "já dito" (condição essencial de qualquer discurso, uma vez que, se as palavras fazem sentido, é porque já fizeram antes e alhures) remete à própria lógica de estabilização de significados em que se inscrevem os sujeitos em busca de uma realidade a ser vivida, de narrativas em que se fixar a fim de realizar a própria existência, construindo enredos sobre si. (GOMES, 2008:46)

\section{Parricídio e topologia da moral: um crime onde não deveria estar}

Sob esse viés, pensamos, como especificidade motivadora da presente análise, nas formas de representação/encenação, no campo midiático, dos estatutos da violência e do ideal adolescente na contemporaneidade. Para tanto, circunscrevemos como objeto de análise reportagens que trouxessem como assunto o parricídio. A escolha temática deve-se à crença de ser esse tipo de crime (ou antes, as figurativizações discursivas que dele são feitas) exemplo propício a se observar com nitidez a dinâmica de restrição/constrangimento inerente ao movimento de dispersão discursiva (tomada aqui no sentido de movimento que envolve, contorna e enforma as práticas sociais, sem, entretanto, deter o próprio fluxo) que enceta relações de poder. Isso porque o parricídio, em princípio, atenta contra formações socialmente consagradas, estabilizadas: a família, as relações hierárquicas verticalizantes, o princípio da "espera", da paciência (em oposição à redução radical do intervalo entre desejo e posse), do próprio nome do pai como metáfora amplamente empregada pela psicanálise como base de uma interdição (o lugar da Lei, de onde emanariam as demais restrições reguladoras dos agrupamentos humanos), mas também como aspiração, ideal e possibilidade irredutível de uma organização social (FREUD, 1913;1999).

O parricídio, conforme adquire existência discursiva em uma materialidade midiática específica (as revistas semanais de informação), deixa antever certos rituais de interdição pela palavra: quem tem direito a voz? Quem perde esse direito (se é que alguma vez o teve)? Quais as imagens que se mobilizam em relação aos executores e às vítimas nesse tipo de delito? Mais importante ainda: quais são as vontades de verdade que, tais como anteparos, estão implicadas de maneira a normatizar/enquadrar comportamentos e crenças, em termos de uma (sobre)vivência de valores nos quais se assenta a sociedade contemporânea?

É pertinente sublinhar que uma análise mais ampla conduzida em outra oportunidade (tendo como objeto matérias jornalísticas que correspondessem ao intervalo entre 1968 e 2002, nas revistas semanais de informação Veja, IstoÉ e Época) tornou possível verificar que, no tipo específico de mídia em questão, o parricídio apenas adquiriu estatuto discursivo (só se converteu em notícia) quando esteve patente uma frustração em termos daquilo que comumente é esperado: um crime que ocorre fora de um espaço previsível de realização.

Foram assim, selecionadas, duas matérias jornalísticas publicadas pela revista Época, tangentes ao assassinato de Manfred e Marísia Von Richthofen, em outubro de 2002. Sobrevém como protagonista nessas narrativas a personagem Suzane Louise Von Richthofen, filha do casal e condenada pela Justiça, em 2006, a 39 anos de prisão em regime fechado, além de seis meses adicionais em regime semiaberto, pela participação no crime, ao lado do então namorado, Daniel Cravinhos de Paula e Silva, e do irmão dele, Cristian. A escolha dos objetos responde a uma observação peculiar tangente às intenções deste artigo: publicadas na mesma revista, com intervalo temporal de apenas 28 dias, as reportagens, em sua 
superfície textual, parecem operacionalizar de maneira diferente as interdições que concorrem para conferir posições de legitimação e "deslegitimação" (bem como para demarcar o lugar do desvio em relação à norma) no que diz respeito àqueles que emergem como executores do crime.

O desconforto adjacente a um tipo de violência que, na regra das expectativas (enquanto jogos de imagem que aderem a determinadas representações sociais), se apresenta "em um lugar onde não deveria estar" (na classe média, perpetrado por uma garota de "bom nível sociocultural") provoca asserções imediatas, o que é visível na primeira das reportagens ("Matou os pais e foi ao motel", Revista Época, 11/11/02). Publicada logo após o assassinato, a matéria estrutura-se em termos da mobilização de estereótipos e mesmo de preconceitos, dando respaldo ao estatuto de que a profanação, a degradação de um espaço referencializado pela normalidade (o da família Von Richthofen, especificamente no que se refere a Suzane) se dá por meio do contágio (ELIAS \& SCOTSON, 2000) com aquilo que vem do âmbito da desordem, da anomia, do radicalmente "diferente", do lugar do "outro" na contrapartida ao espaço ordeiro e normatizado do "nós" (aqui correspondente ao universo figurativo dos Cravinhos).

A insuportabilidade da ideia de uma "ruptura de pacto" por parte da personagem Suzane inviabiliza, no entanto, as articulações mais imediatas e mais óbvias - tanto quanto mais fortemente orientadas pela inicial comoção na esfera pública - apresentadas na primeira reportagem. A segunda matéria, então, emerge com a manchete "A verdadeira história" (Revista Época, 09/12/02), buscando um efeito de sentido de mais neutralidade, sem explicitar de maneira tão ostensiva as coordenadas que imergem os personagens Daniel e Cristian Cravinhos no amálgama dos desvios (o que se coaduna a uma consequente naturalização discursiva de um crime que, afinal, seria coerente com uma espécie de geografia da "imoralidade", em consonância às expectativas reconhecidas na lógica das estratificações: o espaço figurativizado como a periferia, ainda que, em termos de proximidade objetiva, não esteja assim tão distante do que ora se configura como o centro).

Trata-se, então, de tanto quanto possível "domesticar" o desvio, investindo o parricídio em uma ordem de filiações que, se não é suficiente para arrefecer a força das imagens de perversão e crueldade, ao menos reúne as sobras do horror, redimensionando-as em discursos administráveis, capazes de suturar o espaço vazio, lócus do inominável. Como no célebre aforisma de Foucault (2002:6), "é preciso pronunciar palavras enquanto as há".

\section{Dado do mundo, visada de mundo}

Tangenciamos anteriormente a ideia de que o dado do mundo assenta-se em (ao mesmo passo em que constrói) plataformas que determinam historicamente as matrizes de verdade de cada época e de cada lugar. E o efeito mesmo dessa operação consiste em um estatuto de "dado do mundo": um eis, um posto sobre o qual assentamos nossas narrativas, nossas visadas de mundo, nossas formas de existência. Conformando-nos ao posto, perdemos de vista a dimensão do suposto, qual seja, a da possibilidade de existirem maneiras diferentes de organização da coletividade, dos modos de vida.

Ora, como condição essencial a esses patamares de cultura que regem os modos de ser, temos uma ordem específica, fundante, que organiza as trocas sociais pelo estabelecimento de um marco de início, de um grau zero, das "atividades sociais aparentemente homogêneas entre si" (LÉVI-STRAUSS, 1974:24): a ordem simbólica. Estatuto que substantiva a materialidade do mundo, o simbólico operacionaliza isolamentos de campo: as coisas como as concebemos só são reificadas quando recebem um nome que as destaca de uma continuidade, em um processo regido pela diferenciação. Para que algo exista, há de ter aderido ao anteparo do simbólico.

Condição constitutiva dos sujeitos - por "isolar, diferenciar e organizar o campo do vivido" (GOMES, 
2008:32), essa ordem pressupõe, concomitantemente, que os referidos isolamentos de campo subsumam a atribuição de significados a tais experiências, dimensionando-as em termos de um sentido e de uma valoração social. Está implicada aí, mais uma vez, a lógica das estratificações, constituída em vista de uma ordem imaginária: na medida em que o agenciamento de significados trabalha por mobilizar imagens que conferem ao sujeito representações acerca de si e do mundo vivido, tal dinâmica possibilita um efeito de estabilização - instalam-se assim as matrizes de crenças e, sobretudo, de saberes que tornam possível nossa existência em termos de um duplo sintagma: "eu sou, isto é". Se, a um tempo, a ordem simbólica operacionaliza um recorte, uma demarcação, o imaginário, como virtualidade de toda a significação possível, (re)compõe uma espécie de totalidade: a mesma que sustenta aquilo que vivemos, aquilo em que acreditamos.

A construção de identidades individuais e coletivas, nesse sentido, deriva-se imediatamente da articulação simbólico-imaginário: uma estabilização (sempre precária), que confere um efeito de rotina às representações sociais, inserindo-as em um panorama de expectativas, ao mesmo tempo em que são convertidas em fenômenos naturais do mundo. De volta, pois, ao universo das mídias (e, em especial, à temática do parricídio), interessa-nos a depreensão das referidas coordenadas de crença/valoração que, a rigor, dizem respeito a certos aspectos do verdadeiro de nossa época. Isso porque, além de esse tipo de crime (como toda e qualquer experiência humana, afinal) responder em termos da alocação de sentidos a uma ordem de mundo instalada, ainda articula outra especificidade: a de nomear o que, em princípio, é inominável.

Recuperemos a metáfora do "nome do pai" como instalação de uma Lei da qual emanam as interdições que regulam e orientam a constituição da vida social, o parâmetro das trocas simbólicas. Na égide do parricídio como construção discursiva, subjaz o tema da rasura sobre a lei fundante, a hipótese de subversão desse lugar. O parricídio fala, pois, a uma incorporação-apropriação do nome do pai ("agora a lei sou eu"), redimensionando - em termos de figurativizações midiáticas - aquilo que diz respeito, contemporaneamente, às construções imaginárias que sustentam um ideal de adolescência que se prolongaria vida afora como índice ou sintoma de nossa época:

Uma cultura em que a autonomia e a independência são os valores centrais e mais exaltados só pode se transmitir por um duplo vínculo, ou seja, por uma consignação paradoxal e contraditória. A virtude essencial que deve ser ensinada é, com efeito, a capacidade de desobedecer. Portanto, obedecer é desobedecer. Mas - complicação - quem desobedece está obedecendo. Difícil tanto obedecer quanto seu contrário. (CALLIGARIS, 2000:29)

O paradoxo inerente a uma cultura que promove como ideal a rebeldia à norma ao mesmo tempo em que cerra fileiras na defesa - em nome de um consenso, de uma homeostase social - de suas instituições (em que se sublinhem os efeitos de coerção moral, de abdicação das inspirações individuais como tributo inevitável à coletividade) aparece de maneira extrema nas figurativizações midiáticas sobre o parricídio. Entre a premência do dever em relação à sociedade (na forma de princípios e valores) e a injunção do protagonismo (na forma de uma identidade permanentemente em construção, responsabilidade irrevogável de um sujeito que deve contrariar a predestinação e "se transformar naquilo que é"), encenase a vontade de verdade de nossos tempos.

\section{“Matou os pais e foi para o motel": ideal adolescente e quebra de pacto}

A primeira das reportagens contempladas para esta análise tem como chamada de capa: "Matou os pais e foi para o motel - a tragédia da estudante que ajudou a planejar o assassinato do pai e da mãe com uma barra de ferro". Veiculada na edição 234 da Revista Época (11 de novembro de 2002), a matéria abrange 7 páginas (36-42). As cores predominantes na composição da capa são o vermelho e o preto 
(notadamente, o preto ao fundo e o vermelho na porção principal das letras da manchete - "Matou os pais (...)" - , assim como na tonalidade da fotografia que ocupa o centro da capa: a do rosto da personagem Suzane chorando, em close, com a feição transtornada).

Todas as letras em vermelho que compõem a chamada principal são maiúsculas, em uma ordenação tipológica bastante afim à de certas publicações da imprensa dita sensacionalista. Em termos de efeitos de sentido, articula-se nessa materialidade discursiva (a capa da publicação) uma marcação bastante sensível no que diz respeito aos universos da normalidade ("pais", "estudante") e do desvio ("matou", "motel", "assassinato", "barra de ferro"). O fato de o assassinato ser representado como uma tragédia na vida da estudante possibilita a relação com a ideia de fatalismo, própria a esse gênero. Na perspectiva aristotélica sobre a tragédia (Aristóteles, s/d), a trajetória do herói, que no geral se desenvolve em uma direção que vai do polo da glória (eudaimonia) para o da desgraça (daimonia), tem como substrato uma falha ou erro estrutural, conhecido como harmatía. Este se refere, principalmente, a um juízo equivocado, não raras vezes respaldado pela ignorância do herói sobre sua própria origem. Ora, aqui a eventual ignorância da personagem em relação à origem não advém do âmbito do desconhecimento propriamente dito (a exemplo do que acontece com o Édipo de Sófocles), mas de uma certa perturbação em vista da legitimidade do "lugar da origem" como inviolável. No caso de Suzane, a falha estrutural, conforme será constantemente reiterado no corpo da reportagem, explica-se em virtude da profanação pelo contato com o universo anômico e obscuro dos irmãos Cravinhos.

Ainda em relação à chamada de capa, vale observar uma referência intertextual com um título específico do cinema marginal: "Matou os pais e foi ao cinema", filme de Júlio Bressane, lançado em 1969, que traz como enredo a história de um rapaz que mata os pais e vai ao cinema assistir a "Perdidos de amor". Alude-se aqui a um intervalo moralmente intransponível entre matar os pais e ir ao motel, ao menos em termos de uma normalidade que se espera. Eis então uma espécie de frustração da relação causalconsecutiva: é justamente tal efeito de desvio que, entretanto, parece colocar em perspectiva certas representações sociais que mostram explicitamente as demarcações de ordem imaginária que contornam a figurativização do crime: suas motivações, seus executores, suas vítimas.

A análise do corpo da reportagem detém-se inicialmente no próprio título da matéria: "Monstro em casa". Tal figurativização deixa patente uma forma bastante corriqueira de se equacionar, no universo simbólico, algo que é inerente a uma dimensão a ele exterior: o real. Local por excelência daquilo que não se reduz, não adere às filiações do simbólico e não se deixa nomear/normatizar (por dizer respeito a algo que ainda não foi isolado de um continuum), o monstro é uma forma, ainda que cambiante, de se articular algum efeito de previsibilidade: o da instalação de um significante como forma de se esquadrinhar um lugar dentro da rede do simbólico - para além da qual qualquer experiência humana sobrevém como radicalmente impossível.

Em busca da nomeação, ou seja, de estratégias de sutura para o buraco do real - ora identificado com a materialidade do assassinato contra o casal Von Richthofen - é estabelecida na matéria uma fronteira bastante reconhecível em termos de "o espaço dos outros" e o "espaço do nós". Dessa maneira, as representações que se fazem aderir aos irmãos Cravinhos (que, por sinal, são coextensivas a toda a família deles) deslancham narrativas que remetem a uma origem "naturalmente" afim ao crime e ao desvio: "[Manfred e Marísia] queriam ver Suzane longe daquele rapaz que não estudava, não tinha emprego fixo e levava um padrão de vida inferior" (p.38); "A aversão ao rapaz aumentou quando descobriram que ele era usuário de maconha" (p.39); "Desconfiados, [os policiais] descobriram que [a motocicleta] acabara de ser comprada por Cristian - um desses jovens tão incertos que, entre outras coisas, chegou a ser informante da própria polícia" (p.41); "[Cristian] chegou a dar três versões sobre a compra da moto até admitir que era dele o dinheiro. Nessa hora, seu pai, Astrogildo Cravinhos de Paula e Silva, saiu da sala acabrunhado, sentindo que o filho havia sido apanhado" (p.41); "Os irmãos Cravinhos eram considerados 
delinquentes na vila em que moravam com os pais desde a infância. São dez casas iguais numa travessa estreita e sem saída, onde todos se conhecem há muito tempo" (p.41); "Daniel e Cristian tocavam bateria, cantavam alto, gritavam palavrões e fumavam maconha com frequência, segundo os vizinhos" (p.41); “[os irmãos], segundo os vizinhos, jamais foram contidos pelos pais" (p.42).

Sublinha-se, por meio destes exemplos, a asserção de uma verdade segundo a qual o crime só invade o lugar normatizado da classe média como produto de uma influência malévola inerente à massa indiferenciável ("dez casas iguais numa travessa estreita e sem saída"), conforme se explicita, ainda no texto da reportagem, em: "Apesar da crueldade dos irmãos Cravinhos, o que mais choca no assassinato dos Richthofen é a participação da filha". Crueldade que, de resto, não chegaria a ser tão perturbadora caso se tivesse mantido no âmbito em que é valorada como regra, não como exceção.

A se ter em vista a já citada interdição pela palavra, é interessante observar, na matéria, quem são as personagens legitimadas como fontes de informação - expressas pela denotação do discurso reportado (por meio da transcrição literal de suas declarações, o que se verifica pelo uso do sinal gráfico das aspas). Assim, apenas personagens relacionados ao campo de autoridade das instituições sociais (dois delegados do Departamento de Homicídio e Proteção à Pessoa e uma promotora de Justiça) ou aqueles pertencentes ao círculo da família Richthofen (o sócio de Manfred e uma colega de faculdade de Suzane) são os que recebem "direito a voz". As fontes de informação referentes às narrativas específicas sobre os Cravinhos são submersas em um universo de desqualificação em virtude de uma origem obscura, pouco específica e, a rigor, não nomeada ("segundo os vizinhos", "os moradores da vila", "um deles"). Sublinhe-se ainda em relação a essas fontes anônimas que em nenhum dos casos o discurso delas aparece transcrito de forma literal, sendo sempre reconstituído pela instância enunciadora da reportagem.

O efeito contrastante emerge a partir das designações tangentes à família Richthofen e, especialmente, a Suzane: "Bonita, alegre e rica, Suzane não trabalhava, tinha automóvel e tudo o que queria, além de um futuro promissor (...). Estudante do $1^{\circ}$. ano de Direito da Pontifícia Universidade Católica, uma das melhores faculdades de São Paulo, faixa preta de caratê, é fluente em inglês, alemão e espanhol. Seu único problema doméstico conhecido era a implicância dos pais com o namorado" (p.39).

Rica e com boa formação cultural, sobre essa personagem recai (ainda que matizada pela pretensa influência de Daniel Cravinhos) o estigma da ruptura de pacto: encarnando o ideal adolescente típico de nossos tempos, Suzane, entretanto, perturbou inexoravelmente o precário equilíbrio de forças que contempla, por um lado, a euforização de valores como a individualidade e o arrivismo e, por outro, a ideia de sacrifícios individuais como herança de uma aventura coletiva que parece cada vez menos plausível. Se o espetáculo de felicidade como derivação de uma ilusória "adolescência para sempre" nos parece altamente sedutor, o avesso desse espetáculo advém com o reconhecimento de que, afinal, os meandros da perversão não são assim tão alheios a todos e a cada um de nós.

\section{"A verdadeira história": redenção possível}

A segunda reportagem que compõe o corpus desta análise foi publicada na edição 238 da Revista Época, que circulou em 9 de dezembro de 2002 e abrange 6 páginas (84-89). Com a chamada de capa "A verdadeira história", o texto ainda apresenta a linha fina (segunda chamada): "A PM costumava ser chamada para apartar as brigas do pai de Suzane com o namorado dela. Até hoje o órfão de 15 anos visita a família dos irmãos assassinos. Usuária de maconha, Suzane diz que os pais bebiam muito". O texto traz também, limitada por uma caixa gráfica em vermelho, a palavra: "exclusivo".

Orientada por um efeito de sobriedade que destoa da capa da primeira reportagem analisada, nesta materialidade discursiva predominam os tons de branco e cinza. Também aqui, ao centro da página, 
aparece uma fotografia de Suzane - ora sem a expressão facial de transtorno e desalinho. Ao contrário, a imagem sorri placidamente e "olha" para o leitor, porém a figuração lembra muito as fotografias presentes em túmulos e "santinhos" fúnebres. Há, ainda, um contraste de luz e sombra que, semanticamente, reitera o efeito de ambivalência ressonante na composição da capa (e, ademais, em toda a matéria): a personagem oscila entre o "angelical" e o "diabólico". O sintagma verbal que assume maior destaque ("A verdadeira história”) pressupõe assim uma remetência episódica do caso Suzane a um universo estabilizado em termos lógicos, a uma realidade ordenável, administrável e, acima de tudo, reconhecida como verdadeira. Ocorre, no entanto, alguma diluição de fronteiras entre o mundo da nomia e o da anomia, qual eram figurativizados na primeira reportagem.

A impossibilidade de identificação plenamente bem-sucedida entre os acontecimentos e suas formulações discursivas, dessa forma, acaba por desestabilizar a pretensa adesão lógica inicialmente manifesta na chamada de capa. A família Von Richthofen (outrora configurada como vítima) é associada a vícios e brigas (não só em relação ao consumo de maconha, por Suzane, assim como pela constatação de os pais beberem excessivamente). Já a família Cravinhos (anteriormente maculada como a origem dos irmãos assassinos) ora representa o núcleo onde busca segurança o "órfão de 15 anos". O texto imagético compõe a figura da personagem Suzane em tons etéreos (mesmo mórbidos), como se sua própria identidade social se desvanecesse em vista da perturbação de universos estáveis devido ao crime que cometeu. Tal construção discursiva parece reiterar que o fantasma chamado Suzane ainda espreita a sociedade.

Intitulada "No rastro de Suzane", a reportagem busca, então, explicar o fato patente do parricídio, subtraindo-o do espaço nebuloso do real justamente por falar sobre ele (o crime), ou seja, inscrevendo-o em um panorama administrável. Além disso, relaciona a posição do jornalismo (aqui identificado ao aspecto performativo da revista em questão) a um trabalho de investigação, que recomporá a verdade (de maneira "exclusiva", como nos lembra o texto da capa) por meio de um ajuste de fragmentos (Foucault, 2005). É em virtude disso que se potencializam os efeitos de sentido ambíguos da matéria: para sustentar "a verdadeira história" não é mais possível respaldar-se em asserções imediatas do senso comum, como a da menina de natureza exemplar, cuja origem é a "melhor dentre as melhores" da sociedade (Elias \& Scotson, 2000:22-23), mas que foi impelida ao mal pela influência anômica do "pior entre os piores". O discurso estabelecido, então, deve incorporar e neutralizar o desviante como recurso de manutenção de suas formas de poder.

Com uma série de fotografias de Suzane e de Daniel (que incluem, inclusive, momentos da infância de cada um deles), é sensível a polarização da matéria em termos de antes e depois em alusão a um percurso que fez da pequena Suzane a assassina dos pais. Nesse sentido, a palavra "rastro", associada ao tema de animalização, retoma a característica de crueldade tangente ao crime. Como intertítulo da matéria (p. 84), estrutura-se: "Sexo, drogas e brigas familiares na história da menina meiga que tramou a morte dos pais". Em alusão intertextual, há uma subversão do lema "sexo, drogas e rock and roll", identificado à juventude das décadas de 1960 e 1970. A rebeldia própria do estilo musical é agora articulada pela ideia da contestação radical em relação à autoridade verticalizante do nome do pai.

As fotografias dispostas na porção superior de todas as páginas da reportagem buscam reconstituir, por meio dos fragmentos, a narrativa das vidas não só da família Von Richthofen, mas também dos Cravinhos (notadamente, de Daniel): assim, o menino aparece, ainda criança, participando de uma festa de aniversário (p.86) e, mais adiante, rodeado por colegas em uma competição de aeromodelismo (p.88). Há, assim, um esforço em se figurativizar Daniel, diferentemente do que ocorria na primeira das reportagens, no âmbito da normalidade, como reitera a legenda da fotografia: "Esporte - Daniel com amigos em competição de aeromodelismo na Argentina. O rapaz ficou em quinto lugar em uma competição mundial. Antes de conhecer Suzane, treinava todos os dias". O personagem chega mesmo a ser referencializado 
como "o novo amigo da família" (p.88), em alusão à época em que os Richthofen conheceram Daniel, enquanto ele praticava aeromodelismo no Parque do Ibirapuera.

Paradoxalmente, Cristian Cravinhos não é resgatado do campo do desvio e da anormalidade: “(...) chegou a ser internado por dependência de cocaína e vivia às voltas com dívidas com traficantes" (p.88). Entretanto, há uma certa ressonância desse teor desviante também no universo dos Von Richthofen, o que se materializa mais especificamente na construção da personagem Marísia: "Colegas de turma descrevem Lourdes [mãe de Marísia, avó de Suzane] como uma mulher rígida, que costumava punir os alunos com golpes de vara de bambu. Nesses momentos, Marísia gargalhava. 'Ela tinha um prazer sádico em ver os outros sofrendo', conta uma ex-colega" (p.86); "Pessoas que conviveram com ela apontam para um passado com fases complicadas. Filha de descendentes libaneses, Marísia teve uma infância difícil em José Bonifácio, interior de São Paulo" (p.86). Além das demarcações acerca de uma origem biográfica um tanto dúbia, Marísia ainda aparece em uma fotografia, ao lado do marido e do filho Andreas, segurando um copo de uísque. Da mesma forma, a ameaça do desregramento surge, ainda que de maneira menos específica, envolvendo toda a composição familiar: "O lado cinzento da família Richthofen" (p.86); "Só mesmo os integrantes da família Richthofen conhecem o avesso da normalidade que exibiam em público". (p. 87)

A se pensar nas vontades de verdade que sustentam os discursos circulantes, conferindo a eles graus variados de legitimação, esta reportagem se complexifica. Instala-se um desvio em relação aos parâmetros de expectativas socialmente difundidas: o espaço da família nuclear, metáfora da realização de uma autoridade verticalizante, agora é perturbado por determinadas incongruências atribuídas ao cotidiano (e talvez mesmo à origem) dos Richthofen. Em contrapartida, ao espaço outrora anômico dos Cravinhos chega a ser relacionado um aspecto de normalidade, em assunção às referidas expectativas sociais no que é tangente ao universo familiar: "Andreas [Richthofen] tinha no escrivão aposentado Astrogildo Cravinhos, pai de Cristian e Daniel, confiança e apego típicos de um filho. Daniel era como o irmão mais velho. Depois da morte de seus pais, os laços continuaram. Para surpresa dos amigos e parentes, Astrogildo compareceu ao culto de sétimo dia da morte do casal, a convite de Andreas. A perplexidade aumentou quando, na igreja, o menino desgarrou-se da mão do tio Miguel Abdalla (...) e correu para Astrogildo. Abraçados, os dois choraram juntos”. (p.86)

Ancorada em representações sociais que relevam das estratificações próprias à contemporaneidade, esta reportagem aponta, de través, para a desarticulação do nome do pai como indício e fim em si mesmo de uma autoridade outrora inquestionável, ordenadora dos parâmetros que regem a vida da sociedade. A horizontalização das parcerias, sobretudo as familiares (Calligaris, 2002), vem a reboque da positivação valorativa de uma ética da fruição imediata, que torna anacrônica, em vários aspectos, uma ética do dever. O ideal adolescente em nossos tempos, cada vez mais, cimenta esse pressuposto do gozo que não pode ser minimamente adiado, fornecendo à sociedade imagens bastante específicas, donde a quase obrigatoriedade do ser feliz, do estar bem, do ser bem-sucedido - ainda que para isso as pequenas epopéias individuais desconfigurem irremediavelmente qualquer aspiração em termos de um ideal coletivo.

Há, então, um giro de perspectiva tangente às duas concretizações discursivas sobre o parricídio aqui apresentadas. Se inicialmente foi preconizada a recorrência a uma plataforma cultural havia muito estabilizada, referencializando identidades na direção de demarcar e legitimar o lugar da tradição, posteriormente as configurações de discurso aparecem como tributárias de um ideal em que as identidades, constituídas multiplamente como em um jogo, mostram-se esvaziadas de um aspecto de permanência. Isso denota também um decréscimo valorativo, zeitgeist contemporâneo, em relação ao estabelecimento de vínculos sociais mais duradouros, à conformação a certas normas, a tudo quanto atrapalhe a autorrealização e atravanque o caminho - cada vez mais curto - rumo à satisfação. Diluem-se, 
ilusoriamente, as barreiras hierárquicas, e o lugar da Lei é esfumaçado pela tentadora possibilidade de deitar por terra os deveres que subjugam as vontades individuais. Paradoxalmente, no entanto, a premência de agir, de protagonizar, de "ser alguém" passa a representar o dever, com todos os constrangimentos aí implicados. Nas adjacências da père-version (Lacan, 2007), a "versão do pai", segundo a qual cada um pode encarnar a própria lei fundante, insinua-se o fardo de erigir a própria história correspondendo a expectativas sociais tão difusas quanto ambivalentes.

\section{Bibliografia:}

ARISTÓTELES. Arte retórica e arte poética. Rio de Janeiro: Ediouro, s/d

BAUMAN, Z. Em busca da política. São Paulo: Jorge Zahar Editor, 2000 . Modernidade líquida. São Paulo: Jorge Zahar Editor, 2001

CALLIGARIS, C. A adolescência. São Paulo: Publifolha, 2000 Suzane: pano de fundo. Folha de S.Paulo, Ilustrada, 14/11/02

ELIAS, N. \& SCOTSON, J. Os estabelecidos e os outsiders - sociologia das relações de poder a partir de uma pequena comunidade. Rio de Janeiro: Jorge Zahar Editores, 2000.

FOUCAULT, M. Microfísica do poder. $7^{\mathrm{a}}$.edição. Rio de Janeiro: Graal, 1979.

. A verdade e as formas jurídicas. $3^{\text {a }}$.edição. Rio de Janeiro: Nau Editora, 2005

. A ordem do discurso. $8^{\text {a }}$ ed. São Paulo: Edições Loyola, 2002

FREUD, S. Totem e tabu. Rio de Janeiro: Imago, 1999

GOMES, M. R. Comunicação e identificação - ressonâncias no jornalismo. São Paulo: Ateliê Editorial, 2008

HALL, S. “Quem precisa da identidade?”. In: SILVA, T. T. (org.). Identidade e diferença: a perspectiva dos estudos culturais. Petrópolis: Vozes, 2000.

LACAN, J. Escritos. Rio de Janeiro: Jorge Zahar Editor, 1998.

O Seminário, Livro 23: O sinthoma. Rio de Janeiro: Jorge Zahar Editor, 2007.

LÉVI-STRAUSS, C. “Introdução à obra de Marcel Mauss”. In: MAUSS, M. Sociologia e antropologia. São Paulo: EPU/Edusp, 1974.

MOSCOVICI, S. Representações sociais: investigações em psicologia social. Petrópolis: Vozes, 2003.

PÊCHEUX, M. O Discurso: Estrutura ou Acontecimento. $4^{\text {a }}$ Edição. Campinas: Pontes, 2006

SILVA, M. D. J. Em nome do pai: articulações discursivas em matérias sobre parricídio. Dissertação de 
mestrado. São Paulo: ECA-USP, 2007.

ZIZEK, S. Bem-vindo ao deserto do real. São Paulo: Boitempo, 2002.

\section{Mini Currículo :}

Doutoranda em Ciências da Comunicação pela ECA-USP (bolsista CAPES). 